\title{
A Corpus-Based Study of Syntactic Shifts in Chinese-English Conference Interpreting
}

\author{
Lei Gao
}

\author{
School of Foreign Languages, Guangdong University of Petrochemical Technology, Maoming, Guangdong 525000, \\ China \\ Corresponding author. Email: mrgaolei@163.com
}

\begin{abstract}
Due to linguistic differences between Chinese and English, and the expectation of immediate communication effect, syntactic shifts often occur in C-E conference interpreting. Through a self-built parallel corpus, the article investigates the syntactic shifts in terms of mean sentence length, grammatical categories, rhetorical means, and some special sentence structures. Research results show that the occurrence of syntactic shifts enhances the effect, speed and efficiency of C-E conference interpreting by making the interpreted texts simple, concise, explicit, and idiomatic.
\end{abstract}

Keywords: corpus, syntactic shift, Chinese-English conference interpreting

\section{INTRODUCTION}

In C-E conference interpreting, syntactic shift is an important skill for interpreters. According to H. Bussmann [1], syntax has two meanings: 1) It refers to a subcategory of semiotics, involving the order of symbols and the relationship between symbols, abstracted from the relationship between speakers and symbols, the meaning of symbols and symbols, and the relationship between symbols and the external reality of language; 2 ) it refers to a subcategory of the grammar of natural language, a system of rules which describe how all well-formed sentences of a language can be derived from basic elements. The syntactic shift of the article refers to obligatory and optional changes in the construction of sentences in the target language. In order to investigate the syntactic shifts in C-E conference interpreting and find the possible reasons, we built a unidirectional parallel corpus, where Chinese is the source language and English the target language. The size and sources of the corpus are listed in Table 1.

Table 1 Size and source of the corpus

\begin{tabular}{|c|l|}
\hline \multirow{2}{*}{ Size } & 83,654 Chinese words \\
\cline { 2 - 2 } Source & $\begin{array}{l}\text { government leaders' addresses; } \\
\text { reports on the government's work; } \\
\text { press conferences }\end{array}$ \\
\hline
\end{tabular}

\section{THE SYNTACTIC SHIFTS}

Chinese is a kind of paratactic language, so the arrangement of sentences or clauses is linear, and the linkage between them often depends on meaning rather than conjunctions. In contrast, English is a kind of hypotactic language, so the sentences or clauses are usually strung together with certain relative pronouns or conjunctions. In $\mathrm{C}$-E conference interpreting, syntactic shifts often occur due to the syntactic differences between English and Chinese. The article mainly investigates the syntactic shifts in terms of mean sentence length, grammatical categories, rhetorical means, and some special sentence structures.

\subsection{The Mean Sentence Length}

Generally, the mean sentence length (MSL) of translated texts is thought shorter than that of the original texts. S. Laviosa ${ }^{[2]}$ found that the translational component of the comparable corpus of narrative texts has a lower mean sentence length than the non-translational component. But the MSL of the interpreted C-E conference texts in the corpus goes against Laviosa's finding.

As for the MSL of the original press-conference English, K. $\mathrm{Hu}^{[3]}$ did an investigation, which is shown in Table 2.

Table 2 MSL of the original press-conference English

\begin{tabular}{|c|c|c|}
\hline Type & Token & MSL \\
\hline 6,219 & 104,598 & 17 \\
\hline
\end{tabular}

We investigated the MSL of the interpreted press-conference English in our corpus, which is shown in Table 3.

Table 3 MSL of the interpreted press-conference English in our corpus

\begin{tabular}{|c|c|c|}
\hline Type & Token & MSL \\
\hline 3,771 & 33,200 & 18 \\
\hline
\end{tabular}

It is obvious to find that the MSL of the interpreted press-conference English in our corpus is longer than that of the original press-conference English. The main reason 
for this is that the Chinese interpreters wanted to preserve all the information of source language, so they usually took a faithful translation. In addition, Chinese is a kind of paratactic language, so the logical relationship between sentences or clauses is often implicit, getting meanings condensed in short structures. Consequently, for the sake of the audience's understanding, the interpreters tend to add words to explain the Chinese condensed meanings or special cultures. Let us take the interpretation of a sentence for example:

SL: wo men ba fa zhan wen ti fang zai hong guan zheng ce xie tiao tu chu wei zhi, tui dong G20 cheng yuan shuai xian zhi ding luo shi lian he guo 2030 nian ke chi xu fa zhan yi cheng de xing dong ji hua, dai dong quan qiu fan wei de bao rong, lian dong fa zhan.

TL: And we will prioritize development issues in macro policy coordination. We will encourage $G 20$ members to show leadership by developing action plans to implement the UN's 2030 Agenda for Sustainable Development, so as to catalyze inclusive and interconnected development all over the world. (underlined by the author)

Through the addition of these underlined function words and the subject of "we", the logic and meaning of source language are clearly expressed, and the interpretation is made idiomatic. By doing so, most of the interpreted English sentences are longer than their Chinese equivalents. In addition, through the shift of MSL, the interpreted English texts are made explicit in meaning and structure.

\subsection{The Grammatical Categories}

In Chinese, sentences are not usually grammatically marked, but in English, the aspect, tense, voice, logic, and other grammatical categories should be clearly expressed by certain words. Some cases from the corpus are shown in Table 4.

Table 4 Shift in grammatical categories

\begin{tabular}{|c|c|}
\hline $\begin{array}{l}\text { a) xin dong neng } \\
\text { zheng zai cheng } q i \\
\text { fa zhan xin tian di. }\end{array}$ & $\begin{array}{l}\text { New growth drivers are opening } \\
\text { new prospects for China's } \\
\text { development. }\end{array}$ \\
\hline $\begin{array}{l}\text { b) fu pin tuo pin shi } \\
\text { ying ren wu, ge ji } \\
\text { zheng fu yi jing li } \\
\text { xia jun ling zhuang, } \\
\text { bi xu an shi bao zhi } \\
\text { bao liang wan } \\
\text { cheng. }\end{array}$ & $\begin{array}{l}\text { Poverty reduction is a must, } \\
\text { governments at all levels have } \\
\text { made the pledge, and it must be } \\
\text { accomplished both qualitatively } \\
\text { and quantitatively within the } \\
\text { timeframe set. }\end{array}$ \\
\hline $\begin{array}{l}\text { c) dui wo guo fa } \\
\text { zhan qu de de cheng } \\
\text { jiu, quan guo ge zu } \\
\text { ren min bei gan } \\
\text { zhen feng he zi hao! } \\
\text { hui gu guo qu yi } \\
\text { nian, cheng ji lai zhi } \\
\text { bu yi. }\end{array}$ & $\begin{array}{l}\text { These achievements in China's } \\
\text { development, a source of pride } \\
\text { and motivation for our people, } \\
\text { did not come easily. }\end{array}$ \\
\hline
\end{tabular}

In sentence a), the underlined adverb of "zheng zai" is used to modify the verb of "cheng qi" and express a progressive aspect, which is simply interpreted into "opening". Similarly, in sentence b), the underlined adverb of " $y$ i jing", is used to modify the verb of " $l i x i a$ " and express a perfective aspect, which is simply interpreted into "have made". In sentence c), as the object of verb "hui gu", the underlined noun phrase of "guo qu yi nian" expresses a simple past tense, which is simply interpreted into "did". In this way, the interpretations are made explicit in aspect and tense.

In addition, Chinese language does not use passive voice as frequently as English. In our Chinese corpus, there are only 12 sentences in passive voice, while in the parallel English corpus, there are 424 sentences. The reason for the difference is that Chinese language favours personal subjects, while English favours impersonal subjects.

\subsection{The Rhetorical Means}

From a narrow sense, rhetoric can be defined as the study of figures of speech, and from a broad sense, rhetoric may mean the study of how to make a speech or writing effective and attractive. If taken as a part of linguistics, "rhetoric can be seen as a part of the pragmatically grounded text linguistics" ${ }^{[4]}$. All in all, effect of speech or writing is the focus of rhetoric. So interpreters can not ignore rhetoric in interpreting.

The effect of a speech or writing is usually realized through proper linguistic forms. But in a short period of time, how to deal with the rhetorical means constitutes a big challenge for interpreters. In C-E conference interpreting, interpreters are often faced with various rhetorical phenomena. Here, we just take for example of the interpretation of Chinese numeral abbreviations from the corpus. The numeral abbreviations (abbreviated by numbers) are stylistically political expressions in Chinese language, which often appear in statesmen's speeches. The numeral abbreviations are concise in structure, and rich in implication.

In the Chinese corpus, there are altogether 20 numeral abbreviations. They are " $y i$ guo liang zhi", "he ping gong chu wu xiang yuan ze", "yi dai yi lu", "shi san wu", "liang ge yi bai nian", "wu wei yi ti", "si ge quan mian", "yi gong kai", "san qi die jia", "san yan san shi", "san nong", "san ge dai biao", "si feng", "ba xiang gui ding", "shi ba da", "jiu er gong shi", "liu fang hui tan", "san he san hu", and "wu bao hu", of which the numbers are underlined by the author. Research result reveals that interpreters mainly turned to omission, literal translation, and paraphrasing translation.

The methods of omission and literal translation make the interpretations simplified in form and meaning, getting the rhetoric omitted or just the form of rhetorical means produced, and the paraphrasing translation gets the meaning of rhetoric reproduced with its form omitted, making the interpretations explicit in meaning. Rhetorical shifts in C-E Conference interpreting is targeted at good communication effect. 


\subsection{Three Special Sentence Structures}

According to Catford, structure shift is a type of category shift which involves a change in grammatical structure between ST and TT, and structure shift serves as an illustration of the microstructural incompatibility between the linguistic systems of $\mathrm{SL}$ and $\mathrm{TL}^{[5]}$. Due to the differences between Chinese and English linguistic systems, structural shifts often occur during C-E conference interpreting. Here, we just take for example three special Chinese sentence structures, and investigate how they were interpreted.

Firstly, it is the four-character structure in Chinese language. The relationship between these four-character structures should be made clear (coordinative or subordinative) before being interpreted into English in different ways.

As for the coordinative four-character structures, they can be interpreted into different types of English phrases according to the grammatical functions they play in English, which can be shown by the cases underlined by the author in Table 5.

Table 5 Interpretation of coordinative four-character structures

\begin{tabular}{|l|l|}
\hline \multicolumn{1}{|c|}{ Chinese four-character structure } & \multicolumn{1}{c|}{ English interpretation } \\
\hline $\begin{array}{l}\text { da zhong chaung ye } \text {, wan zhong } \\
\underline{\text { chuang xin peng bo fa zhan. }}\end{array}$ & $\begin{array}{l}\text { Business startups and innovations by the general public } \\
\text { flourished. (subject; noun phrase) }\end{array}$ \\
\hline $\begin{array}{l}\text { guo qu de yi nian, ji bu ping fan, } \text { ling } \text { ren fen. } \\
\text { yu shi ju jin, rui yi jin qu. }\end{array}$ & $\begin{array}{l}\text { The past year was truly extraordinary and inspiring. } \\
\text { (predicative; adjective phrase) }\end{array}$ \\
\hline & $\begin{array}{l}\text { Advance with the times and with enterprising spirit. } \\
\text { (predicate, verb phrase) }\end{array}$ \\
\hline
\end{tabular}

From Table 5, it is found when interpreted into English subject, the coordinative four-character structure was interpreted into noun phrase; interpreted into predicative, adjective phrase; interpreted into predicate, verb phrase.

If there is a subordinative relationship between the four-character structures, one of them can be interpreted into the English main clause, and the others into subordinative structures, for example:

SL: mei you gui ju, bu cheng fang yuan.

TL: Nothing can be accomplished without following norms and standards.

In the example above, the main four-character structure of "bu cheng fang yuan" was interpreted into "Nothing can be accomplished", a main clause, and the subordinate four-character structure of "mei you gui ju" was interpreted into "without following norms and standards", a preposition structure.

Secondly, it is the "you"-sentence (the English equivalent for "you" is "have"). A structure formed by "you" in a you-sentence can act as predicate, attribute, and adverbial. The "you" structure is mainly to express a certain degree. But in English, the verb of "have" is seldom used to express a certain degree. Therefore, almost all the "you" structures expressing a certain degree are usually interpreted into other English expressions instead of using the verb "have". Let us take an example from the corpus:

SL: zhong guo jing ji you qian li, you ren xing, you you shi. (underlined by the author)

TL: The Chinese economy possesses potential, resilience, and strengths. (underlined by the author)

Thirdly, it is the "shi"'-sentence. (the English equivalent for "shi" is "be") As a frequently used sentence structure in Chinese, shi-sentence appears 779 times in the corpus. These sentences can be pragmatically generalized into four categories: making a judgment, proposing a goal, making a choice, and laying an emphasis. Accordingly, they are interpreted in different ways, which can be shown by some examples underlined by the author in Table 6 .

Table 6 Interpretation of shi-sentence

\begin{tabular}{|c|c|c|}
\hline shi-sentence & $\begin{array}{c}\text { Pragmatic } \\
\text { function }\end{array}$ & Interpretation \\
\hline $\begin{array}{l}\text { qian jin dao lu } \\
\text { cong lai bu shi } \\
\text { yi fan feng shun } \\
\text { de. }\end{array}$ & $\begin{array}{l}\text { making a } \\
\text { judgment }\end{array}$ & $\begin{array}{l}\text { The road ahead may } \\
\text { not always be as } \\
\text { smooth as we } \\
\text { expect. }\end{array}$ \\
\hline $\begin{array}{l}\text { wen zeng zhang } \\
\text { zhu yao shi wei } \\
\text { le bao jiu ye, hui } \\
\text { min sheng. }\end{array}$ & $\begin{array}{l}\text { proposing a } \\
\text { goal }\end{array}$ & $\begin{array}{l}\text { The aim of } \\
\text { maintaining stable } \\
\text { growth is primarily } \\
\text { to } \\
\text { employment ensure } \\
\text { promote the people's } \\
\text { wellbeing. }\end{array}$ \\
\hline $\begin{array}{l}\text { wo men bu gao } \\
\text { "da shui man } \\
\text { guan" shi de } \\
\text { qiang ci ji, er } \\
\text { shi chi xu tui } \\
\text { dong jie gou } \\
\text { xing gai ge. }\end{array}$ & $\begin{array}{l}\text { making a } \\
\text { choice }\end{array}$ & $\begin{array}{l}\text { Rather than adopting } \\
\text { strong stimulus } \\
\text { policies that would } \\
\text { have } \\
\text { economy-wide } \\
\text { impact, an } \\
\text { continued to move } \\
\text { forward with } \\
\text { structural reform. }\end{array}$ \\
\hline $\begin{array}{l}\text { te bie shi jiu ye } \\
\text { xing shi zong ti } \\
\text { wen ding. }\end{array}$ & $\begin{array}{l}\text { laying an } \\
\text { emphasis }\end{array}$ & $\begin{array}{l}\text { Of particular note, } \\
\text { the employment } \\
\text { situation overall } \\
\text { remained stable. }\end{array}$ \\
\hline
\end{tabular}




\section{CONCLUSION}

By means of a parallel corpus, it is found that due to syntactic differences between Chinese and English, structural shifts are often made in C-E conference interpreting. These explanations are characterized by simplification, explanation and standardization, which makes the interpreted English more authentic and clear in meaning, and greatly improves the effect, speed and efficiency of conference interpretation.

\section{ACKNOWLEDGMENT}

The article is funded by the Social Science Project of Jiangsu Province, China (17YYB002) and GYPT's teaching research project (TDPY201923).

\section{REFERENCES}

[1] Bussmann, H., Routledge Dictionary of Language and Linguistics, translated and edited by G. P. Trauth and K. Kazzazi, Beijing: Foreign Language Teaching and Research Press. 2000, pp. 407-473.

[2] Laviosa, S., Core Patterns of Lexical Use in a Comparable Corpus of English Narrative Prose, Meta. 43(4) (1998) 557-570. DOI: $10.7202 / 003425 \mathrm{ar}$

[3] Hu, K., Critical Readings in Corpus-based Translation Studies, Nanjing: Nanjing University Press. 2012. p. 327.

[4] Bussmann, H., Routledge Dictionary of Language and Linguistics, translated and edited by G. P. Trauth and K. Kazzazi, Beijing: Foreign Language Teaching and Research Press. 2000, pp. 407-473.

[5] Shuttleworth, M. \& M. Cowie, Dictionary of Translation Studies, Shanghai: Shanghai Foreign Language Education Press. 2004, pp. 159-160. 